\title{
The 2019 Mw 5.8 Changning, China earthquake: A cascade rupture of fold-accommodation faults induced by fluid injection
}

\author{
Tao Li ${ }^{\mathrm{a}, \mathrm{b}}$, JianbaoSun ${ }^{\mathrm{a}, *}$, Yuxin Bao ${ }^{\mathrm{a}}$, Yan Zhan ${ }^{\mathrm{a}}$, Zheng-Kang Shen ${ }^{\mathrm{c}}$, Xiwei Xud ${ }^{\mathrm{d}}$, Cecile Lasserre ${ }^{\mathrm{e}}$ \\ a State Key Lab. of Earthquake Dynamics, Institute of Geology, China Earthquake Administration, Beijing 100029, China \\ b Shanxi Taiyuan Continetal Rift Dynamics National Observation and Research Station, Beijing, 100029, China \\ c Earth, Planetary, and Space Sciences, University of California, Los Angeles, California, USA 90095 \\ ${ }^{\mathrm{d}}$ National Institute of Natural Hazards, Ministry of Emergency Management of China, Beijing 100085, China \\ e Univ Lyon, Univ Lyon 1, ENSL, CNRS, LGL-TPE, F-69622 Villeurbanne, France
}

\section{A R T I C LE IN F O}

\section{Keywords}

Changning Earthquake

InSAR deformation

Induced seismicity

Poroelastic model

Sichuan Basin

Folding deformation

\begin{abstract}
A B S T R A C T
Industrial production activities associated with salt mining, hydraulic fracturing, or geothermal exploitation can induce pore pressure and stress field changes, thus inducing seismic activity. Most of the events are not disastrous due to limited energy radiated. Here we report a Mw 5.8 damaging event that occurred in Changning, China on June 17, 2019, probably the largest induced event by industrial exploitation ever recorded. The earthquake is located within the Changning anticline, and it raises great concerns on why and how the event occurred in a relatively quiescent area in terms of tectonic activity. Moreover, it has been debated whether this earthquake ruptured solely on the fold-accommodation faults or also involved a deep-rooted fault under the anticline. By using InSAR data from two satellites, we investigate the detailed rupture and slip pattern of this earthquake. We propose a cascade rupture mode of the fold-accommodation faults, through poroelastic modeling of excess pore pressure by fluid injection and pumping operations and static Coulomb stress calculation on the pre-stressed faults. We argue that water injections may have triggered this event. The result highlights the importance of reassessing seismic hazard over similar tectonic environments with intensive industrial exploitation.
\end{abstract}

\section{Introduction}

Fluid injection linked to wastewater disposal, hydraulic fracturing for shale gas exploitation, mining, and geothermal energy production can increase the pore pressure and reduce the effective stress on faults, thereby inducing earthquakes (e.g., Healy et al., 1968; Raleigh et al., 1976; Segall, 1989; Ellsworth, 2013; Brodsky and van der Elst, 2014). These earthquakes are commonly small to moderate, but in some cases are strong enough to cause severe damages, such as the $2016 \mathrm{Mw}$ 5.8 Pawnee event in Oklahoma, USA, and the $2017 \mathrm{Mw}$ 5.4 Pohang event in South Korea (e.g.,Keranen et al., 2013; Foulger et al., 2018; Kim et al., 2018; Grandin et al., 2017; Fielding et al., 2017). For hazard assessment and mitigation of such earthquakes, many studies have been conducted to understand the geomechanical properties of the environment and inducing mechanisms. The results reveal that induced earthquakes may be related to the criticality of the regional stress level, injection parameters (pressure, volume, rate, and depth etc.), properties of pre-existing faults (scale, density, and maturity, etc.), and fault orientation relative to the tectonic stress (e.g., Ellsworth, 2013; Weingarten et al., 2015; Langenbruch and Zoback, 2016; Lei et al., 2017; Kozłowska et al., 2018; Hincks et al., 2018; Schultz et al., 2018; Kolawole et al., 2019). The induced damaging earthquakes (e.g., $M \geq+5.0$ ), however, are often found to have occurred on pre-existing deep-rooted faults that are connected to the fluid injection zones (e.g., Grandin et al., 2017; Galloway et al., 2018; Kim et al., 2018; Kolawole et al., 2019).

\footnotetext{
* Corresponding author.

E-mail address: sunjianbao@gmail.com (J. Sun)
} 
In recent years, the Changning region at the southeastern corner of the Sichuan Basin, China, has experienced strong earthquake sequences that are ascribed to industrial fluid injection (Figs. 1 and 2a; Lei et al., 2017; Lei et al., 2019a; Meng et al., 2019), such as the Mw 4.7 Junlian event on January 28, 2017, the Mw 5.2 Xingwen event on December 16, 2018, and the Mw 4.8 Gongxian event on January 3, 2019. Following these events, the Mw 5.8 Changning event occurred on June 17, 2019, setting a new record in this region. The event has a strike-slip faulting mechanism with a significant thrusting component, and a shallow centroid depth of $\sim 3 \mathrm{~km}$ (Figs. 2a-2c; Liu and Zahradník, 2020; Lei et al., 2019b; Yi et al., 2019). In the following month after the mainshock, more than 5000 aftershocks were recorded, including more than $15 \mathrm{M} \geq 3.5$ events with mechanisms varying from strike-slip, oblique, to thrust faulting (Lei et al., 2019b; Yi et al., 2019; Lihua Fang, 2019, personal communication). The Changning event caused heavy losses, killing 13 people, injuring more than 200, and seriously destroying numerous buildings.

The Changning event is spatio-temporally correlated with the deep-well salt mining activities which have continued for the past three decades (Sun et al., 2017; Lei et al., 2019b), and is close to the 2018 Mw $\quad 5.2 \quad$ Xingwen event (within $\sim 15 \mathrm{~km}$; Figs. 2a-2b). Lei et al. (2019b) thus argue that this event was probably promoted by both the salt mining water injection and the Coulomb stress loading from the 2018 Xingwen event. In this study, we investigate the geological setting, seismogenic structures, and slip distribution of the Changning event through analyses of geological mapping data, petroleum seismic reflection profiles, and InSAR observations. Our study documents some specific features associated with the origin of the Changning event, which could be valuable for assessment of induced-seismicity hazards in similar tectonic environments.

\section{Tectonic Settings and Salt mining activity}

\subsection{The Sichuan Basin}

The Sichuan Basin is a rhombus-shaped intermontane basin lying between the Tibetan Plateau, the Qinling Range, and the Eastern Yangtze Mountain (Fig. 1). The basin is surrounded by the Micang Shan and Daba Shan thrust faults along its northeastern margin, the imbricated Longmen Shan fault zone along its northwestern margin, the central portion of the left-lateral Xianshuihe-Xiaojiang fault (XXF) system (including the Anninghe-Zemuhe, Daliangshan, and Mabian faults) along its

southwestern

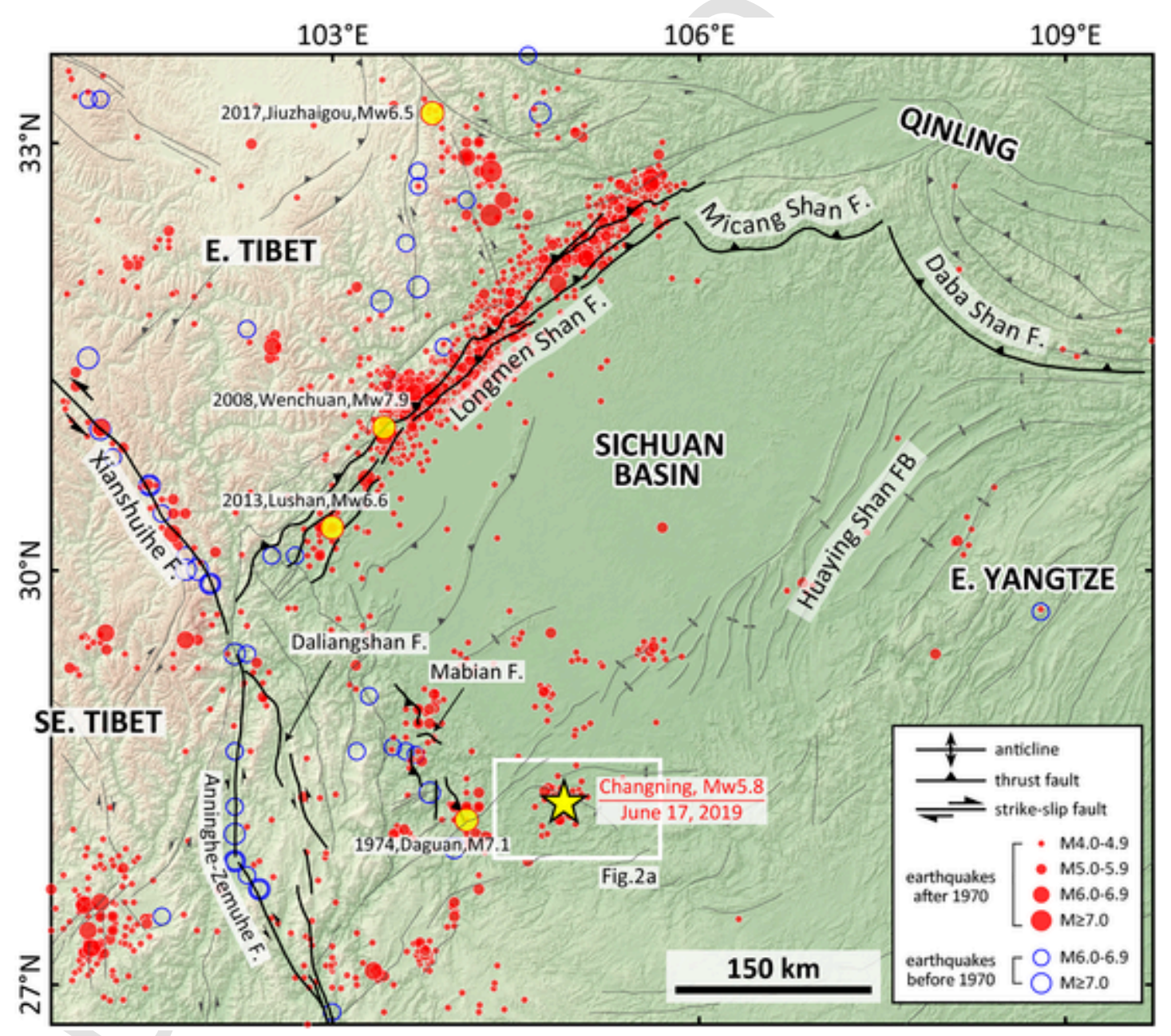

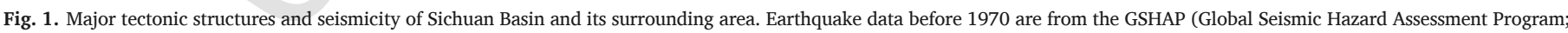

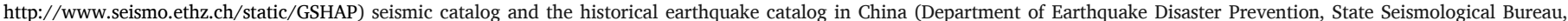

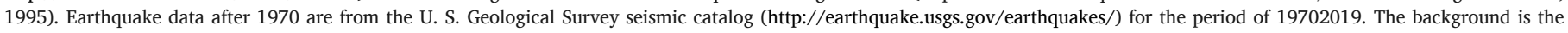
SRTM DEM data (Farr et al., 2007). 

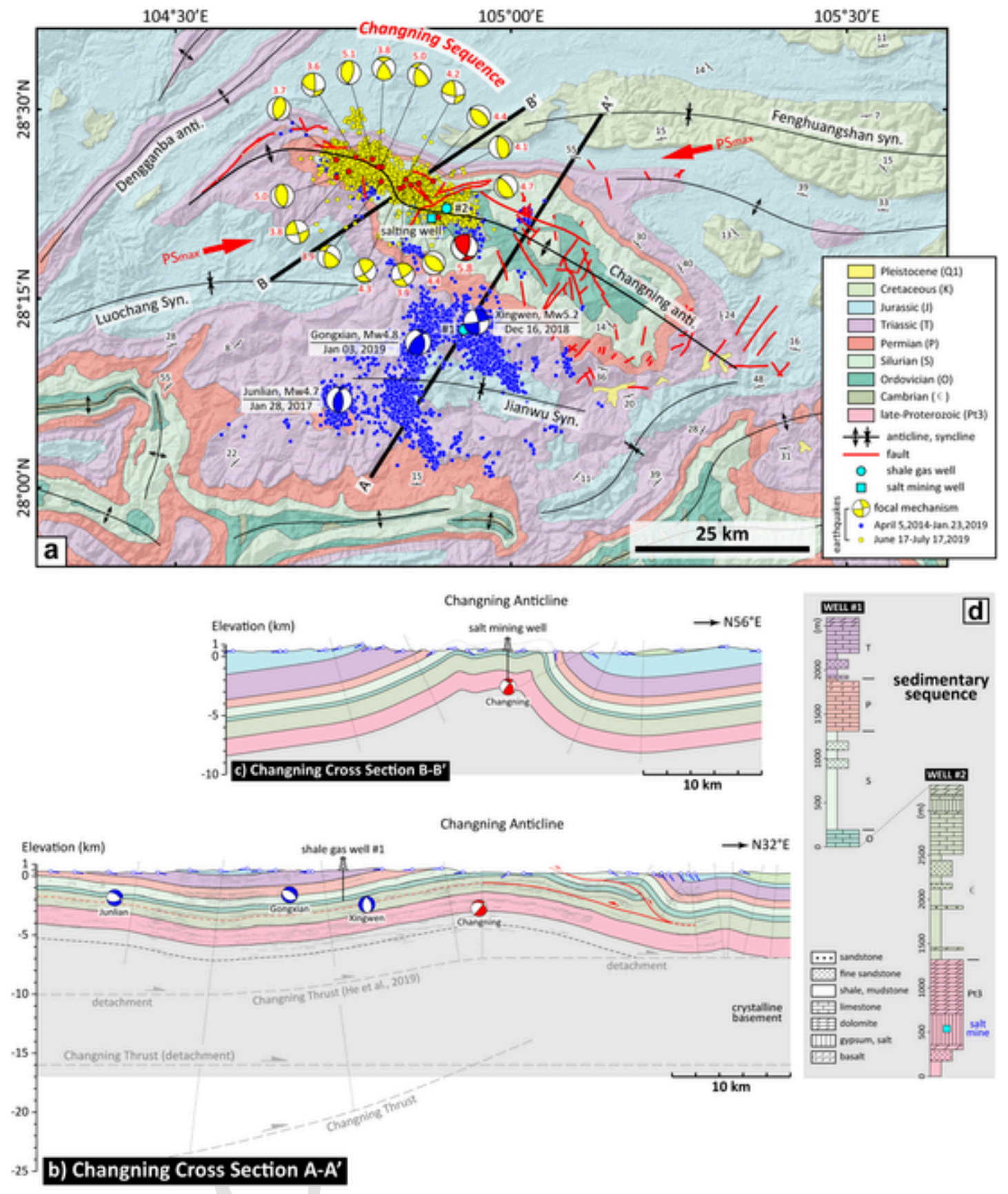

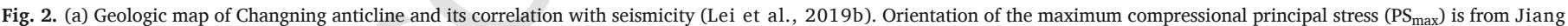

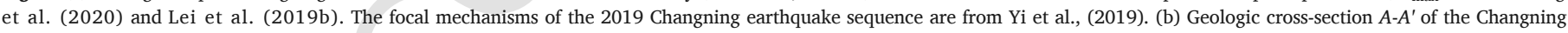

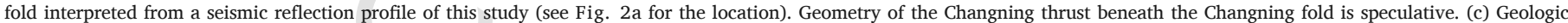

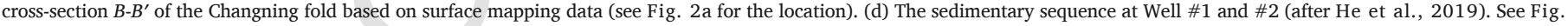
2a for the wells' locations.

margin, and the Huayingshan fold belt along its southeastern margin, respectively. These structures were formed during the Mesozoic (e.g., Burchfiel et al., 1995; Wang et al., 2003), but were reactivated during the Cenozoic in response to the eastward expansion of the Tibetan Plateau (e.g., Burchfiel et al., 1995; Xu and Kamp, 2000; Wang et al., 2014; Yang et al., 2017; Tian et al., 2018). Presently, the structures along the basin's western and southwestern margins are strongly active, as documented by recent large magnitude earthquakes (Fig. 1; e.g., the 1974 M 7.1 Daguan, 2008 Mw 7.9 Wenchuan, and 2013 Mw 6.6 Lushan events; Deng et al., 2003; Xu et al., 2009; Li et al., 2014; Bai et al., 2018). Comparatively, the presently active deformation along the eastern and northeastern margins appears to be weak (Wang and Shen, 2020). 


\subsection{The Changning Anticline}

The 2019 Changning event occurred within the Changning anticline located at the transition zone between the XXF system and the Huayingshan fold belt (Figs. 1 and 2a). The fold exposes Cambrian through Cretaceous strata at the surface. The Cambrian to middle Triassic strata are marine deposits comprising limestone, dolomite, mudstone and gypsum (Fig. 2d; He et al., 2019), above which the upper Triassic to Cretaceous are terrestrial deposits dominated by sandstone and conglomerate (Sichuan Bureau of Geology and Mineral Resources, 1991). Below the Cambrian, the upper Proterozoic comprises dolomite, salt, gypsum and mudstone as revealed by borehole data (Well \#2, Figs. 2b-d). Mechanical-weak units (gypsum, salt, and mudstone) within the upper Proterozoic, lower Cambrian, and Silurian are interpreted to act as regional or local detachment horizons (Fig. 2d; e.g., He et al., 2019).

The Changning anticline extends northwestward for $\sim 60 \mathrm{~km}$, curves to NNW-trending for $\sim 10 \mathrm{~km}$, then curves to $\mathrm{W}$ - to SW-trending at its westernmost segment (Fig. 2a). To the northwest, northeast, and south, the Changning fold joins with NE-trending folds, E-trending folds, and strongly-deformed interference folds, respectively. The fold has a NE-vergent fold geometry overall. According to a petroleum seismic reflection profile $(A-A)$ across the fold's central portion $(\sim 12 \mathrm{~km}$ east of the 2019 Changning event epicenter; Fig. 2b), the southern limb is simple and dips $\sim 11^{\circ}$ to the southwest. Comparatively, the northern limb shows a more complex structure. While the Proterozoic-lower Cambrian strata dip gently $\left(\sim 16^{\circ}\right)$ to the northeast, the overlying upper Cambrian-lower Silurian strata are re-folded along the Cambrian detachment. Cutting through them, a back-thrust ramp (dipping $\sim 50^{\circ}$ to the NE) connects the Cambrian and Silurian detachments, significantly tilting the upper Silurian-Cretaceous strata. At the core of the fold, numerous secondary thrust faults and tight secondary folds can be observed on outcrops (Fig. 2a). Along a structural cross section across the NNW-trending fold portion $(\sim 6 \mathrm{~km}$ west of the 2019 Changning event epicenter; Fig. 2c), the fold has a $\sim 22^{\circ}$-dipping southern limb and $\mathrm{a} \sim 40-70^{\circ}$-dipping northern limb, exhibiting a more tight geometry. The Changning fold is probably controlled by a SW-dipping thrust ramp linking with a lower and an upper detachment (He et al., 2019), by a thrust ramp cutting downward, or by a horizontal detachment (Fig. 2b). Although these three scenarios cannot be distinguished by investigating the shallow fold geometry, the master fault of the Changning fold is definitely deeply-buried ( $\geq 8 \mathrm{~km}$ ).

According to statistic of azimuths of faulting scratches on bedding and fault planes, Jiang et al. (2020) suggest that the present geometry of the Changning fold is probably a result of two stages of deformation. In the first stage, the maximum compressional principal stress on the fold oriented NE, approximately perpendicular to the fold axis at the central portion. In the second stage, the maximum compressional principal stress rotated to ENE, consistent with the modern stress orientation revealed by earthquake focal mechanisms (Fig. 2a; Lei et al., 2019b). The Changning fold shows no clear evidence for recent tectonic activity. However, we argue that it is presently active because of its locating in a region experiencing moderate strain accumulation based on GPS measurements (Wang and Shen, 2020).

\subsection{Salt mining activity}

The Changning salt mine is developed in the upper Proterozoic unit (Figs. 2c-2d). At the core of the Changning fold (Fig. 2c), deep wells are drilled into the rock at depths of $2.5 \mathrm{~km}$ to $3.0 \mathrm{~km}$, and freshwater was extensively injected into the wells for dissolving salt (Sun et al., 2017). Salt mining activities date back to as early as 1990. Long-term water injection significantly enhanced seismicity of the region (e.g., Zhu and He, 2014; Sun et al., 2017).

\section{InSAR Observations and Modeling of Coseismic Deformation}

\subsection{InSAR Observations}

Field investigation after the earthquake shows no surface rupture in the epicenter area around the Shuanghe town (Fig. 3b) except some minor cracks and fissures (Yi et al., 2019). We collect Synthetic Aperture Radar (SAR) data from the Sentinel-1 satellites of the European Space Agency (ESA) and the PALSAR-2 L-band SAR data from the Japan Aerospace Exploration Agency (JAXA) to measure ground deformation and determine the fault geometry and kinematics of the 2019 Changning earthquake. The SAR data are processed using both the Gamma (Strozzi et al., 2008) and JPL/Caltech ISCE (Rosen et al., 2012) software packages, and the latter has a module for ionosphere delay correction for PALSAR-2 ScanSAR data (Liang and Fielding, 2017). Detailed processing steps are given in the supplementary materials.

The PALSAR-2 interferograms in both ascending and descending tracks show relatively clear fringe patterns, although the data pairs span 2-3 years (Figs. 3b-3c). Sentinel-1 interferograms show fringe patterns consistent with PALSAR-2 ones. However, they suffer from significant coherence loss in the near-field and show stronger atmospheric disturbance (Fig. S1). The eastern half of the two PALSAR-2 interferograms (near the mainshock epicenter, Figs. 3b-3c) shows a prominent lobe of positive displacement in the line of sight (LOS) of the satellite, indicative of ground motion toward the satellite that can be attributed to uplift. The larger LOS displacement observed for this lobe on the descending track (with respect to that on the ascending track) implies an additional contribution in the interferogram from a component of left-lateral strike-slip. The western half of the interferograms (close to the June 22, 2019 aftershock epicenter, Figs. 3b-3c) shows another lobe of positive LOS motion in both tracks, also suggesting uplift of the ground. Besides these two major western and eastern uplift patterns, a SSW-NNE gradient of LOS displacement, with low amplitude and reversed signs on the descending and ascending tracks, is also observed. This more distributed deformation pattern indicates left-lateral motion across the WNW-trending anticline.

\subsection{Inversion of Fault Geometry and Slip-distribution}

\subsubsection{Fault model}

The eastern and western uplift patterns are modeled by slip on two fault segments bounding to the north uplift zones (segments 1 and 3, respectively, Figs. 3b-c). The left-lateral displacement across the fold is modeled by oblique slip on fault segment 1 and pure sinistral slip on fault segment 2, respectively (Figs. 3b-3c). However, it is 

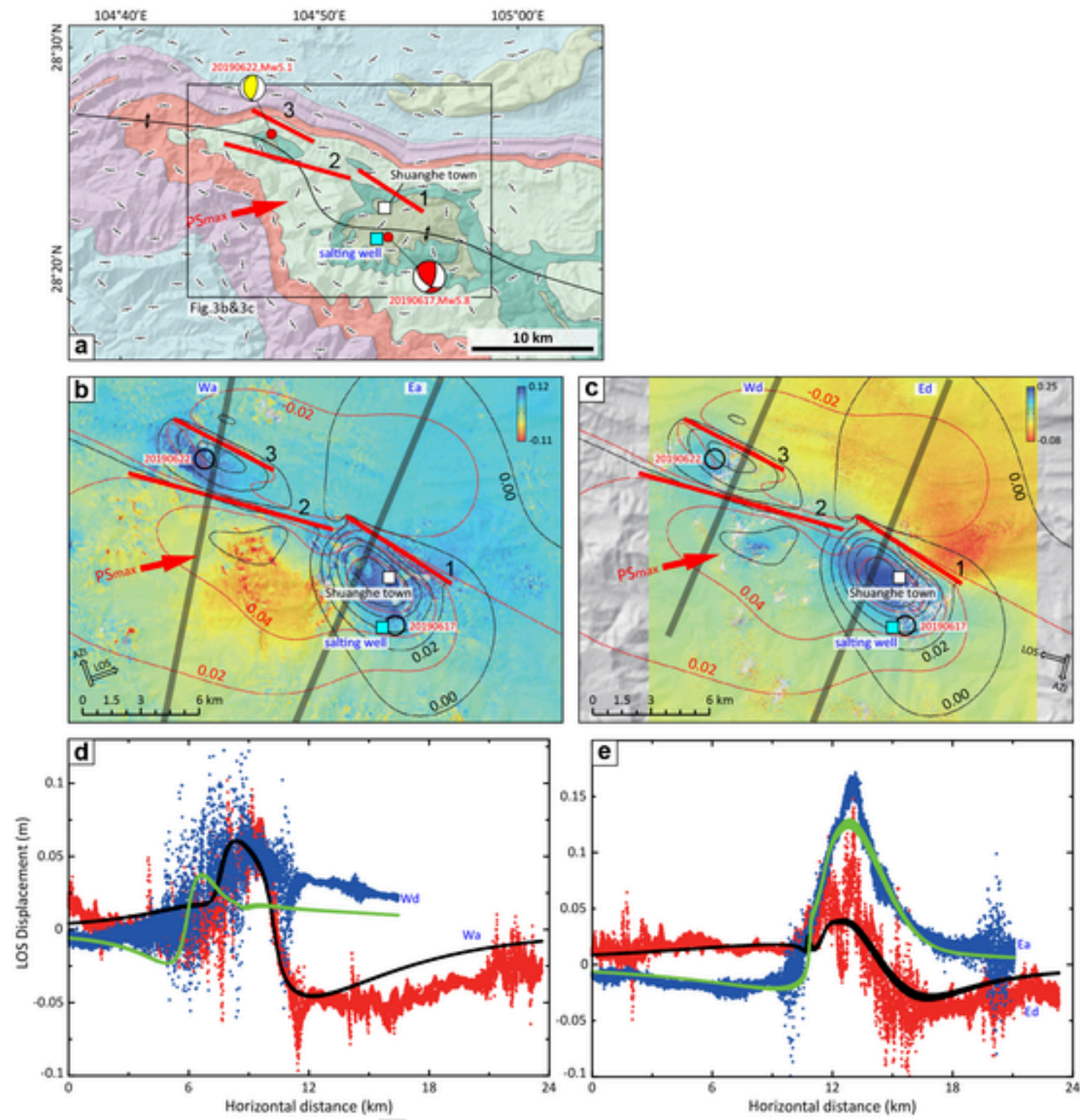

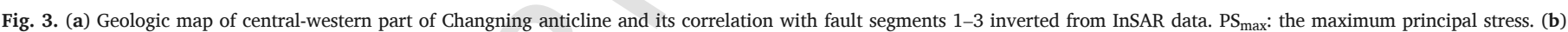

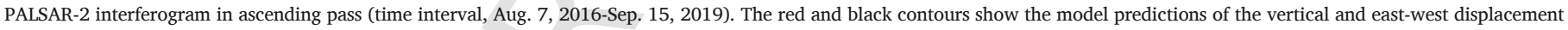

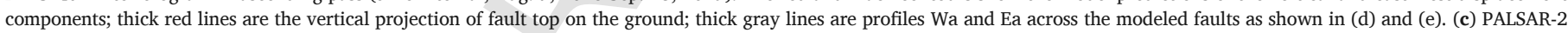

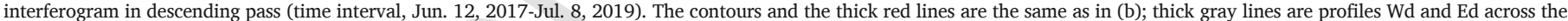

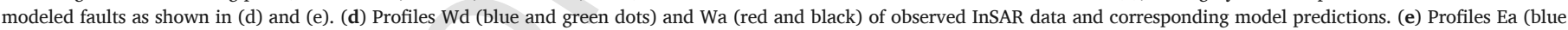

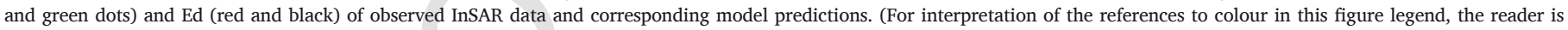
referred to the web version of this article.)

difficult to precisely determine the location and strike of segment 2 from InSAR data only, as the phase gradient across the fault remains rather smooth on the interferograms. The relocated aftershocks extend northwestward from the mainshock hypocenter and are at greater depth (Yi et al., 2019; Lihua Fang, 2019, personal communication). They indicate a sub-vertical fault plane extending to a depth of $\sim 1-10 \mathrm{~km}$ (Fig. 4a). Combining both the aftershock and InSAR data, we infer fault segment 2 as a sub-vertical fault, buried at $0.5 \mathrm{~km}$ depth and with a width of $10 \mathrm{~km}$ (Fig. 4a).

\subsubsection{Inversion results}

We use all four pairs of InSAR data from both descending and ascending passes in our inversion. By fixing the locations of fault segments at the surface, we invert for the fault dips and slip-distribution on individual fault planes simultaneously using a maximum-a-posteriori probability method (Fig. 4a; Sun et al., 2013). The optimal fault dips are highly variable, with $31^{\circ}, 90^{\circ}$, and $64^{\circ}$ for the fault segments $1,2,3$, respectively. The uncertainties of the dipping angles are listed in Table S2. The parameter convergence processes are shown in Fig. S2 and S3. The trade-offs between parameters are also provided in Fig. S4. Our solution thus contrasts with the double couple solution from 


\section{a) Changning Coseismic Slip Distribution}

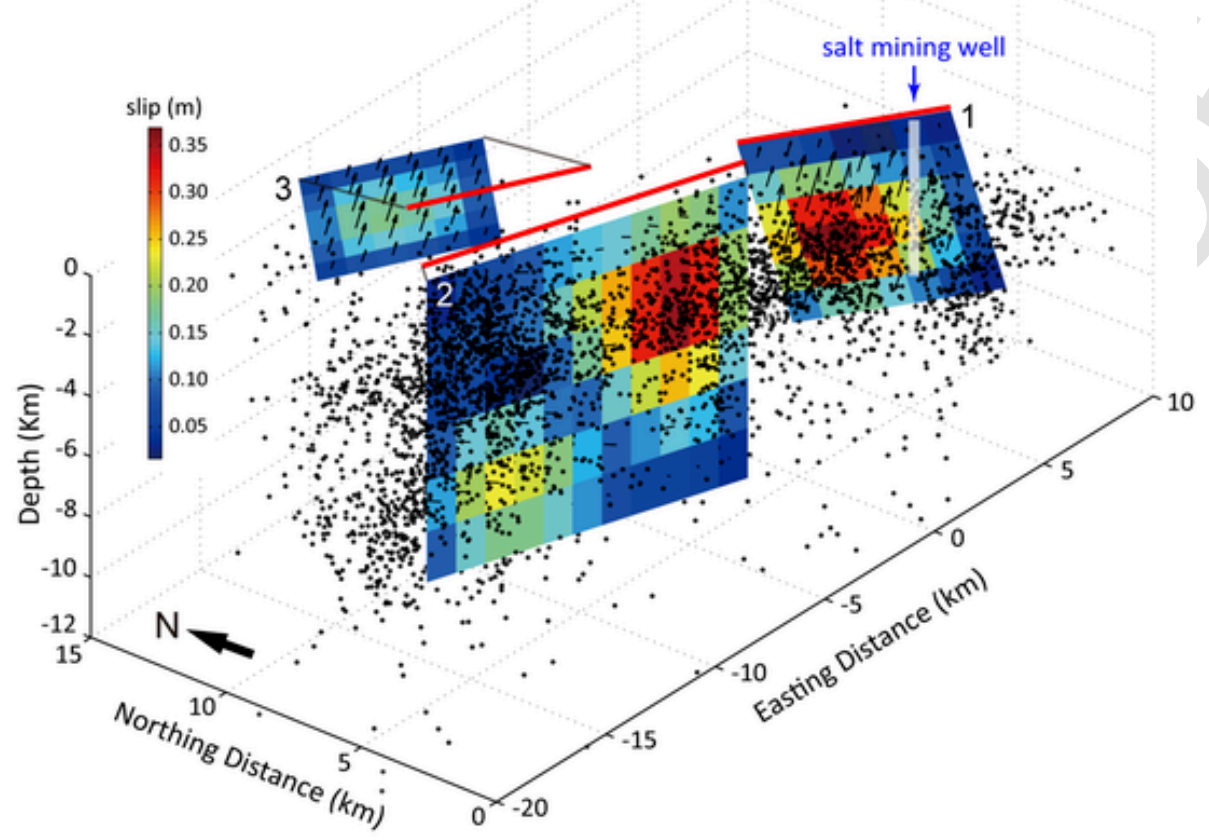

b) Coulomb Stress Change at $\sim 15^{\circ}$ Rake

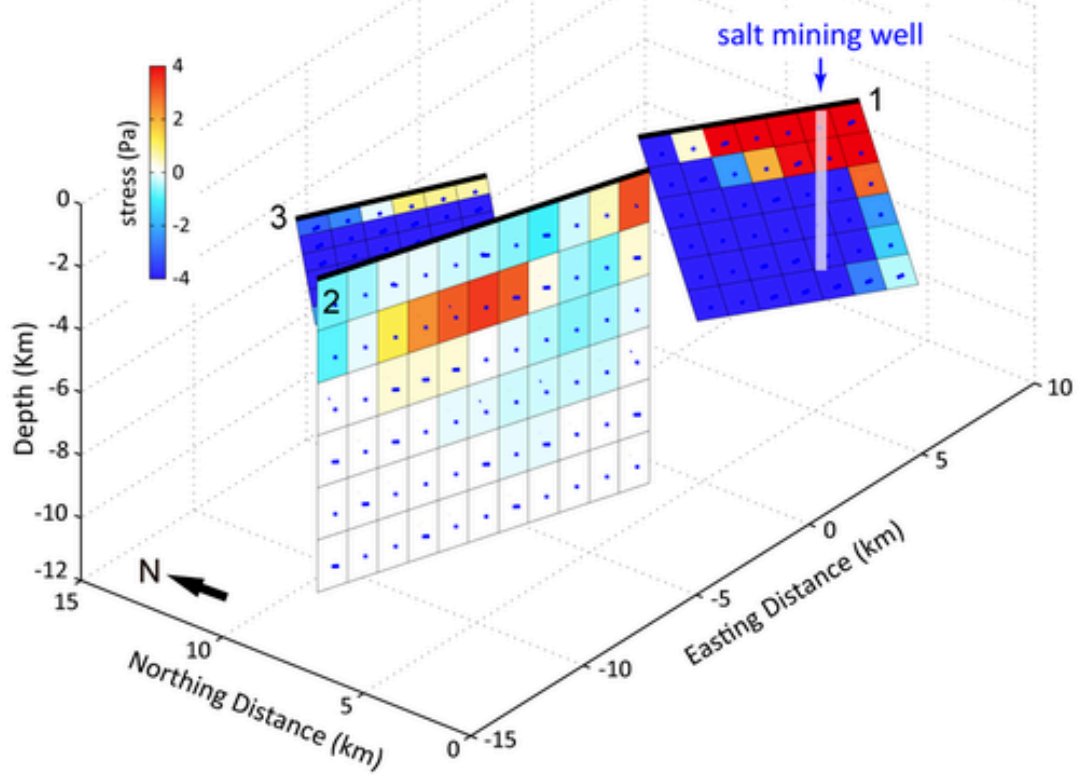

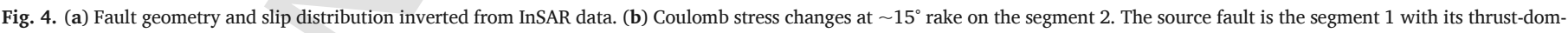
inated slip distribution, and segment 2 and 3 are the receiver faults.

seismic data, which shows strike-slip dominated faulting with significant thrust component on a unique $51^{\circ}$ south-dipping fault (Yi et al., 2019). Our slip model satisfactorily fits all of the four independent InSAR observations, and the model predictions match well the deformation patterns in both near- and far-fields (Fig. 3d, e, and S1). The PALSAR-2 data profiles across the Changning anticline axis in both the eastern and western sides also show good fitting (Fig. $3 \mathrm{~d}$ and e), except the western profile in descending pass (Fig. 3d), where the data suffer from stronger decorrelation effects and show greater scattering along the profile. A visible residual feature can be seen on the descending track of the Sentinel-1 interferogram near segment 1 (Fig. S1), which could be due to phase unwrap- 
ping errors given the low signal-to-noise ratio of this interferogram and strong water vapor delays. Overall, we argue that the current model is optimal for the Changning event because it can recover the most significant deformation features observed on the 4 independent InSAR interferograms.

Slip on segment 1 has an average rake of $\sim 64^{\circ}$, indicating a significant oblique thrust motion on this south-dipping fault plane, and a maximum slip of $\sim 37 \mathrm{~cm}$ at a depth of $\sim 2.1 \mathrm{~km}$ (Fig. 4a). It is directly under the Shuanghe town, which suffered the most severe damages and casualties during the Changning event. The hypocenters located by different groups are close to this segment, and the earliest aftershocks also concentrated around this area (Yi et al., 2019; Lihua Fang, 2019, personal communication). Therefore, we infer that the earthquake nucleated on segment 1 , then propagated to the west as illuminated by aftershock migration (Fig. 4a; Lihua Fang, 2019, personal communication; Li et al., 2020 ). The seismic moment on this segment is $\sim 1.9 e+17 \mathrm{Nm}$, corresponding to a Mw 5.4 event, similar to the Pohang event (Kim et al., 2018). However, it represents only $26 \%$ of the total seismic moment released $(\sim 7.4 \mathrm{e}+17 \mathrm{Nm})$ during the Changning earthquake sequence.

Slip on segment 2 shows two slip concentration areas on the vertical fault plane (Fig. 4a). The eastern one, close to segment 1 , has a maximum slip of $\sim 35 \mathrm{~cm}$ at a shallow depth of $\sim 3-5 \mathrm{~km}$. The second one occurs at the western and deeper part of the fault plane, and has a maximum slip of $\sim 24 \mathrm{~cm}$ at a depth of $\sim 7-9 \mathrm{~km}$. The slips are predominantly sinistral. No significant slip appears at shallow depth. The slip-distribution pattern is overall consistent with the distribution of aftershocks, which deepen gradually from east to west (Fig. 4a; Lihua Fang, 2019, personal communication). The strike-slip dominated features of segment 2 in our model can also be seen with the time-series analysis of Sentinel-1 InSAR data in both ascending and descending passes (Fig. S5), which are consistent with the single-pair InSAR observations (Fig. 3) but with reduced errors and averaged deformation signals spanning the Changning earthquake. The seismic moment release on segment 2 is $\sim 4.9 \mathrm{e}+17 \mathrm{Nm}$, representing $\sim 66 \%$ of the total moment release. Therefore, the geodetic data support a strike-slip dominated fault slip of the Changning earthquake (Fig. 4a), while a simple thrust-dominated fault model (e.g., Wang et al., 2020) may not be consistent with the observations, and is also incompatible with the seismic data inversion results (e.g., Liu and Zahradník, 2020; Li et al., 2020). The total moment release due to slip on segments 1 and 2 accounts for $\sim 92 \%$ of the energy released during the Changning event. The extra south-dipping fault segment 3 is introduced for fitting the deformation pattern to the NW corner, which most likely corresponds to the Mw 5.1 aftershock (seismic moment $\sim 5.6 \mathrm{e}+16 \mathrm{Nm}$ ) on June 22,2019 , as identified from its spatial location (Fig. 3a) and given its quite similar magnitude. Note that the geometry of segment 3 is inferred from InSAR data only due to large uncertainty of seismic data around this area.

\section{Discussions}

\subsection{Cascade rupture during the Changning event}

Large induced earthquakes can lead to severe damages due to the shallow depth of their sources. The pre-condition for such destructive events is the pre-existence of faults close to failure (e.g., Grandin et$$
\text { al., }
$$

2017). ducing mechanisms are usually invoked. One involves stress changes exceeding the strength of faults due to nearby mining activities, through elastic or poroelastic stress transfer processes. Another is pore pressure increase along faults by direct fluid pressure diffusion through highly permeable medium driven by injections (Ellsworth, 2013). We first evaluate the excess pore pressure at the inverted hypocenter of the Changning earthquake related to fluid injection and pumping operations in a poroelastic medium, to investigate whether human activities increased the pore pressure at nearby earthquake hypocenter. Then the static Coulomb modeling approach in elastic medium is applied to test the triggering relationship between the different segments involved in Changning earthquake rupture as identified in section 3.2.

\subsubsection{Pore pressure change due to fluid injection and pumping operations}

Due to minimal information available about the salt mine production in the vicinity of the Shuanghe town and the seismic region of the Changning earthquake, we implement a first-order modeling for evaluating the influences of salt mining on the generation of the event. Though the spatial proximity of the injection spots to the earthquake fault is clear from our geodetic modeling results, we still lack information such as drilling of the fault core and high-precision relocated aftershocks etc. Therefore, we rely on the poroelastic deformation model to calculate the excess pore pressure loaded by salt mining activities at the hypocenter. Here we adopt a high-efficient semi-analytic method called POEL to solve the Biot equations (Biot, 1941) for excess pore pressure distribution in a layered poroelastic half-space (Wang et al., 2003). The salt mine is composed of three pairs of injection and pumping wells, and each pair of wells is horizontally connected at depth with one well for injection and another for pumping (Sun et al., 2017). The dual-well mining technique replaced the single-well convection technique in May 2004 for increasing productivity, and all of the wells have used dual-well technique since the end of 2012. The spatial configuration of the wells is shown in Fig. 5, C2 and C6, C5 and C8, and C9 and $\mathrm{C} 10$ are three connected pairs of wells, and the fluids flow from the injection wells to the pumping wells (see arrows for flow directions in Fig. 5). From our modeling of seismogenic faults (Fig. 4a), the salt well bottoms are approaching the fault surface at the southeastern corner of segment 1 (Fig. 4a), within a distance of $\sim 120-250 \mathrm{~m}$ considering the modeling uncertainties. The crustal layering structure is obtained from borehole data given in Fig. $2 \mathrm{~d}$, which is provided by the shale gas companies. The rock material property constants of the layered crust model are adopted according to the typical values from literature (e.g., Manoochehr et al., 2016). The injection and pumping rates are assumed to be constants as the time-varying information is not available after 2013. Here we adopt the average rate of $25 \times 10^{4} \mathrm{~m}^{3} /$ month of 2013 for both injection and pumping wells (Sun et al., 2017) and ignore the previous operations. The input parameters for POEL software are provided in Table S3. The closest hypocenter of the Changning earthquake to fault segment 1 is from Yi et al. (2019). It is within $\sim 500 \mathrm{~m}$ from our resolved fault surface using InSAR data, and is $\sim 2.0 \mathrm{~km}$ from the wells' bottom.

The excess pore pressures from 6 wells are calculated in an axisymmetric and isotropic medium so that the fluid excess pore pressure applied on the earthquake initiating point by injection or pumping could be quantitatively 


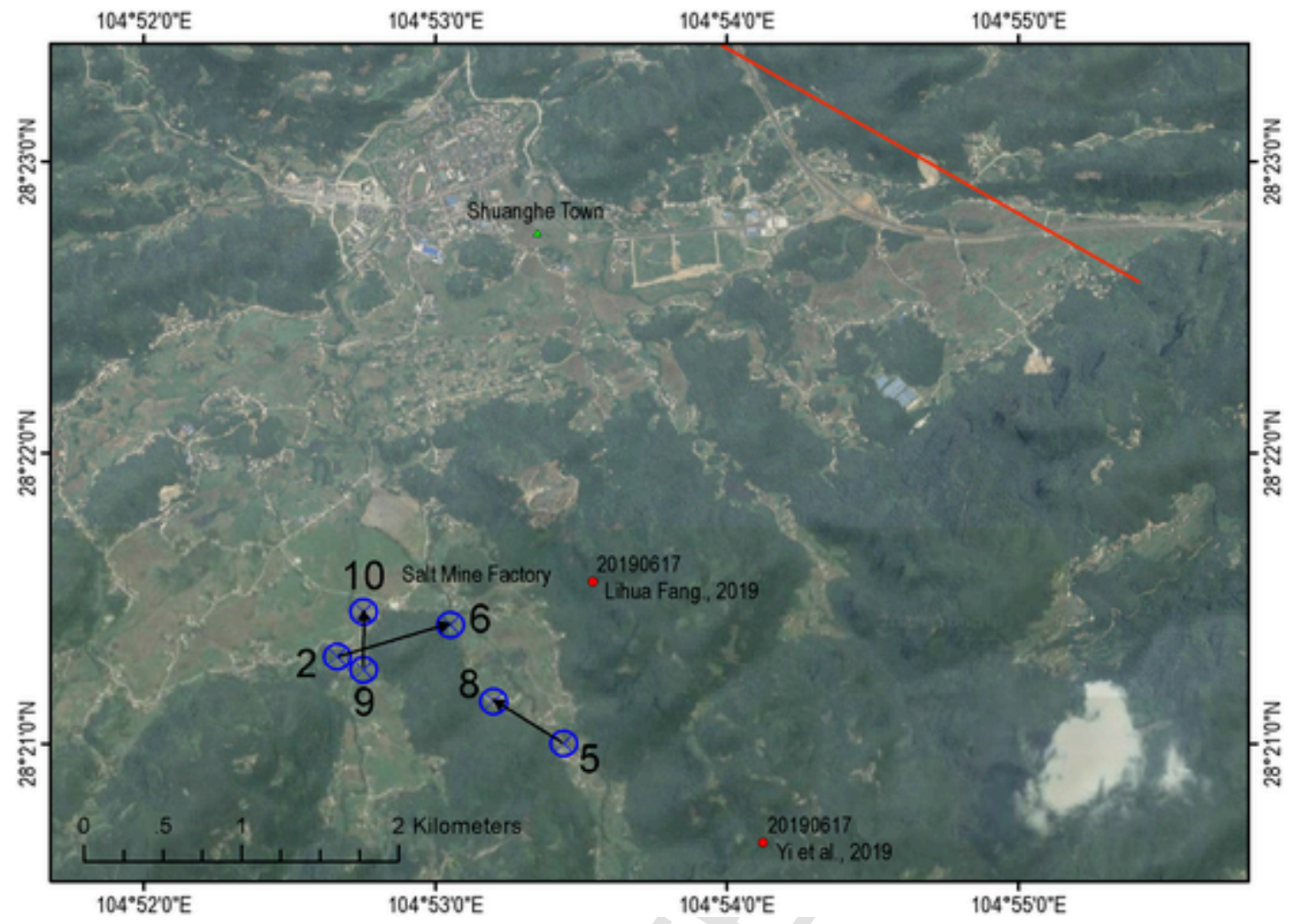

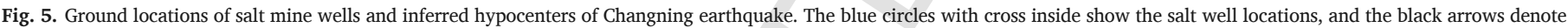

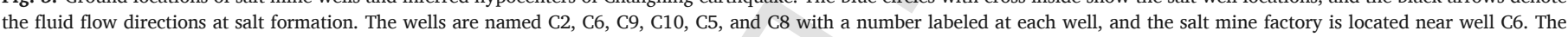

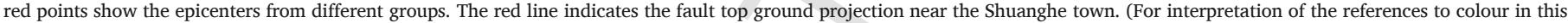
figure legend, the reader is referred to the web version of this article.)

evaluated. We show the accumulated excess pore pressures of the 6 wells in Fig. 6 after a 6.5-year simulation period until June 2019. The injection and pumping are in operation simultaneously, and they have reverse pore pressure effects on the surrounding medium through fully coupled poroelastic deformation behaviors (Fig. 6). In absence of detailed production data available, we mainly consider the influence of the spatial location of the sources on the initiation point, assuming constant fluid rates, and ignoring the contributions from possible horizontal connections of the wells inside the salt formation. Fig. 7 shows the time-dependent behaviors of the excess pore pressures at the hypocenter from the 6 wells during the 6.5 -year continuous injection and pumping operations before the Changning earthquake. The positive and negative values indicate increasing or decreasing excess pore pressures. Their different magnitudes mainly reflect the spatial separation of the sources and the target, with the well C5 having the most significant contribution to the excess pore pressure given that well $\mathrm{C} 5$ is the closest one to the hypocenter. By summing the contributions from all of the 6 wells, the excess pore pressure at the hypocenter was approaching $\sim 0.5 \mathrm{MPa}$ before the earthquake, indicating significant promotion of failure by fluid injection from the wells (Fig. 7a). It is also clear that the Noordbergum effects occur at the early stage ( $0-15$ days) of the injection/ pumping operations (Fig. 7b), which is a typical feature of poroelastic response to external stress disturbance in layered formations (Wang and Kumpel, 2003). According to the injection data before 2013 (Sun et al., 2017), the significant fluid loss occurred in 2007, but it is reduced to a low level of about $0.5 \times 10^{4} \mathrm{~m}^{3} /$ month thereafter. To investigate the effects of water loss on excess pore pressure at the hypocenter, we apply a water loss of $0.5 \times 10^{4} \mathrm{~m}^{3} /$ month at the 3 pumping wells (C6, C8, and $\mathrm{C} 10)$. The summing excess pore pressure due to water loss becomes stable at $\sim 0.4 \mathrm{MPa}$ after a short time, and it is still a significant effect for excess pore pressure increase at the hypocenter at the time of the earthquake (Fig. 7c). A valuable test is to adjust the spatial location of the wells to investigate the influences of the source locations on the excess pore pressure at the hypocenter. Hence we deliberately move the well C5 away from the hypocenter to check the variation of the final excess pore pressure superposition. The result shows that it becomes stabilized at $-0.6 \mathrm{MPa}$ under the new configuration of the wells (Fig. $7 \mathrm{~d}$ ). The test clearly indicates that the spatial separation between the wells and the hypocenter may be crucial for induced seismicity initiation in poroelastic medium.

\subsubsection{Effect of pore pressure change on seismogenic fault}

The Changning earthquake area lies in a region with distributed faults with variable geometries within active folds (Fig. 2a), providing the prerequisites for hosting small-scale induced seismicity (e.g., $<$ M3.0). However, whether and how large and destructive earthquakes may nucleate and evolve within such folds remains poorly known. Our fault model used to invert the InSAR observations involves three disconnected fault segments. As shown in Fig. 3a, a group of salt mine wells is located $\sim 4 \mathrm{~km}$ south of the surface trace of segment 1 , which is 

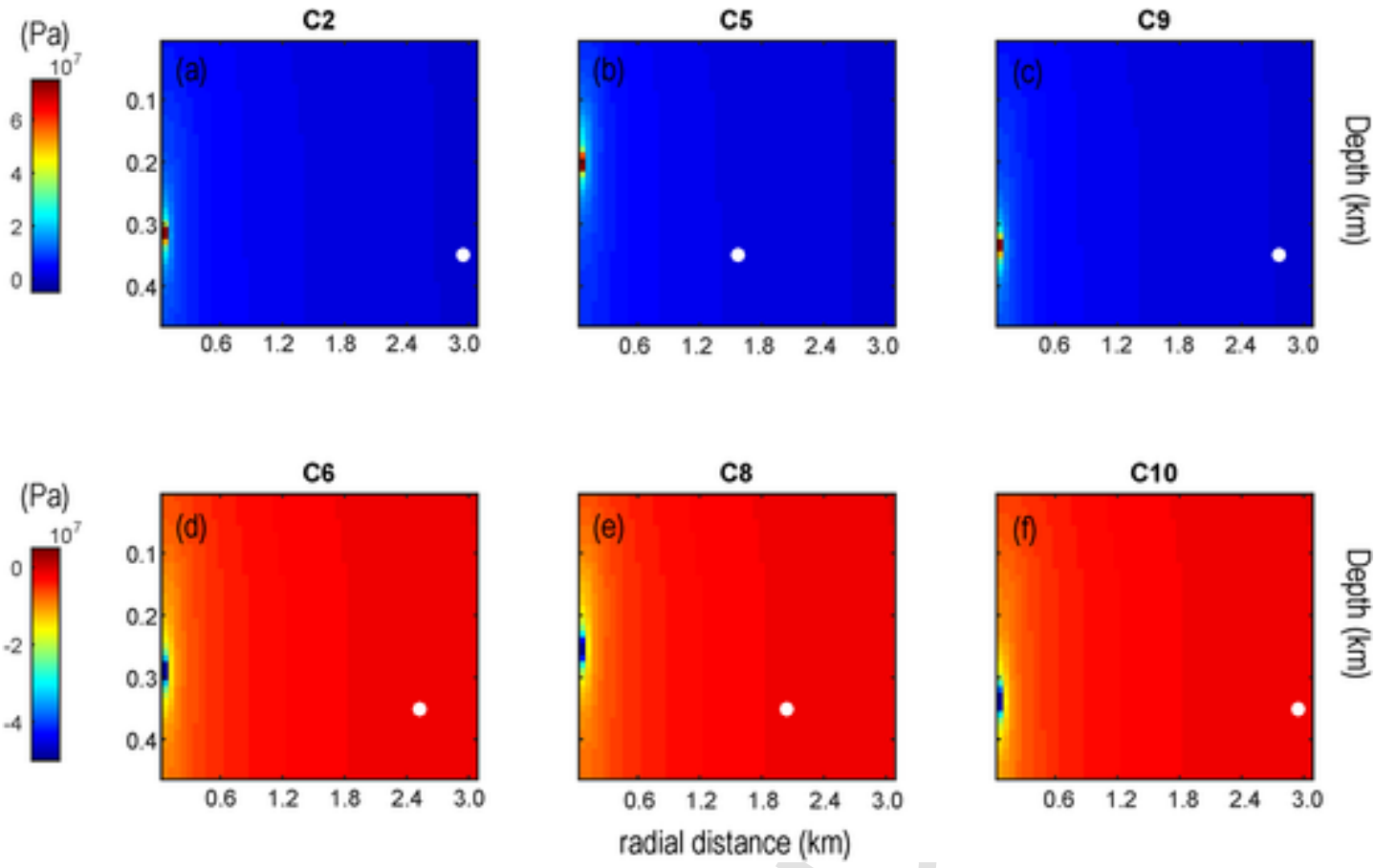

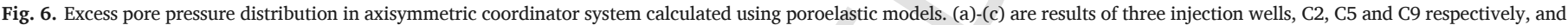

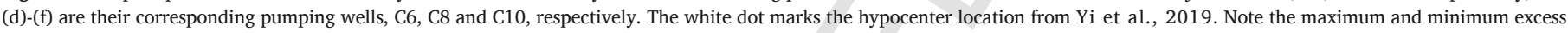

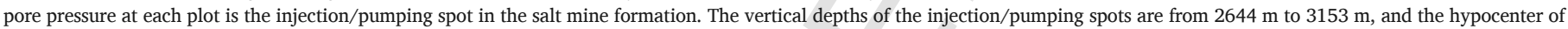
the Changning earthquake is at $3000 \mathrm{~m}$.

$\sim 31^{\circ}$ dipping to the south with its top fixed at $100 \mathrm{~m}$ below the surface. Given the uncertainties of the fault parameters, we estimate a vertical distance of $2.38-2.75 \mathrm{~km}$ between the well locations at the surface and the fault plane at depth (Fig. 4a, see supplementary for uncertainty discussions), which is quite consistent with the reported water injection depths of 2.5-3.0 km of salt mine company (Sun et al., 2017; Lei et al., 2019b). It is therefore plausible to infer that massive water injection (e.g., $14.0 \times 10^{4} \mathrm{~m}^{3} /$ month peaked at 2007 and abrupt water loss of $6.0 \times 10^{4} \mathrm{~m}^{3}$ at the same time, $25.5 \times 10^{4} \mathrm{~m}^{3} /$ month peaked at 2012; Sun et al., 2017) induces pore-pressure perturbations around and on segment 1 . It likely triggered micro-seismicity since then, and also the fault rupture in the 2019 Changning event under the Shuanghe town according to the poroelastic modeling presented in section 4.1.1. This inference may also be supported by the fact that the injection spots at depth and the hypocenter depth of the earthquake are $\sim 2.0 \mathrm{~km}$ apart (Fig. 4a), although the relocation uncertainties are relatively large due to seismic data limitations (Lihua Fang, 2019, personal communication; Yi et al., 2019). However, we show that the rupture did not remain confined to a unique host fault segment in the vicinity of the injection site after its initiation. Such a propagation during induced seismicity episodes is of great concern, as discussed by Avouac (2012), although it was not observed during the Oklahoma and Pohang events (Grandin et al., 2017; Kim et al., 2018).

\subsubsection{Cascade rupture of earthquake due to Coulomb stress triggering}

Our result shows that the rupture propagated from segment 1 to segment 2, leading to a more disastrous Mw 5.8 event. To better understand why the fault rupture could propagate from an oblique-thrust fault segment to a strike-slip fault segment, we calculate the Coulomb static stress changes on segment 2 due to slip on segment 1 using the Coulomb stress evaluation software of King et al. (1994). We assume a left-lateral slip mechanism for segment 2 with a $15^{\circ}$ rake and a friction coefficient of 0.4 (we also test different values of friction coefficient but find no significant changes on the result). The Coulomb stress change is positive on the fault patches of segment 2 at shallow depth $(<4 \mathrm{~km})$, and the largest stress change exceeds 4 bars (Fig. 4b). It is well above the threshold for static stress triggering effects (King et al., 1994). Therefore, we propose a rare cascade rupture mode with multiple fault segments and multiple triggering mechanisms involved during the Changning earthquake inside of an anticline fold. It could start with a sub-event induced by pore-pressure changes, followed by a second sub-event triggered by static stress changes. The finding is well supported by a recent seismological inversion result, which shows that the event is composed of a thrust sub-event and a following strike-slip sub-event so that a non-double couple component is notable from the mainshock (Liu and Zahradník, 2020). Unlike the 2016 Pawnee, Oklahoma earthquake, where the water injections reached the deep-rooted basement fault and directly triggered a Mw 5.8 earthquake (Grandin et al., 2017; Fielding et al., 2017), the Changning earthquake occurred within the Changning anticline with a more complex rupture behavior. Difference in the rupture mode at the two sites is likely due to the differences in their tectonic environments, and this study highlights a cascade-rupture mode, demonstrating how a small-scale induced seismicity could evolve into a disastrous event, by rupturing multiple faults developed in active folds. 

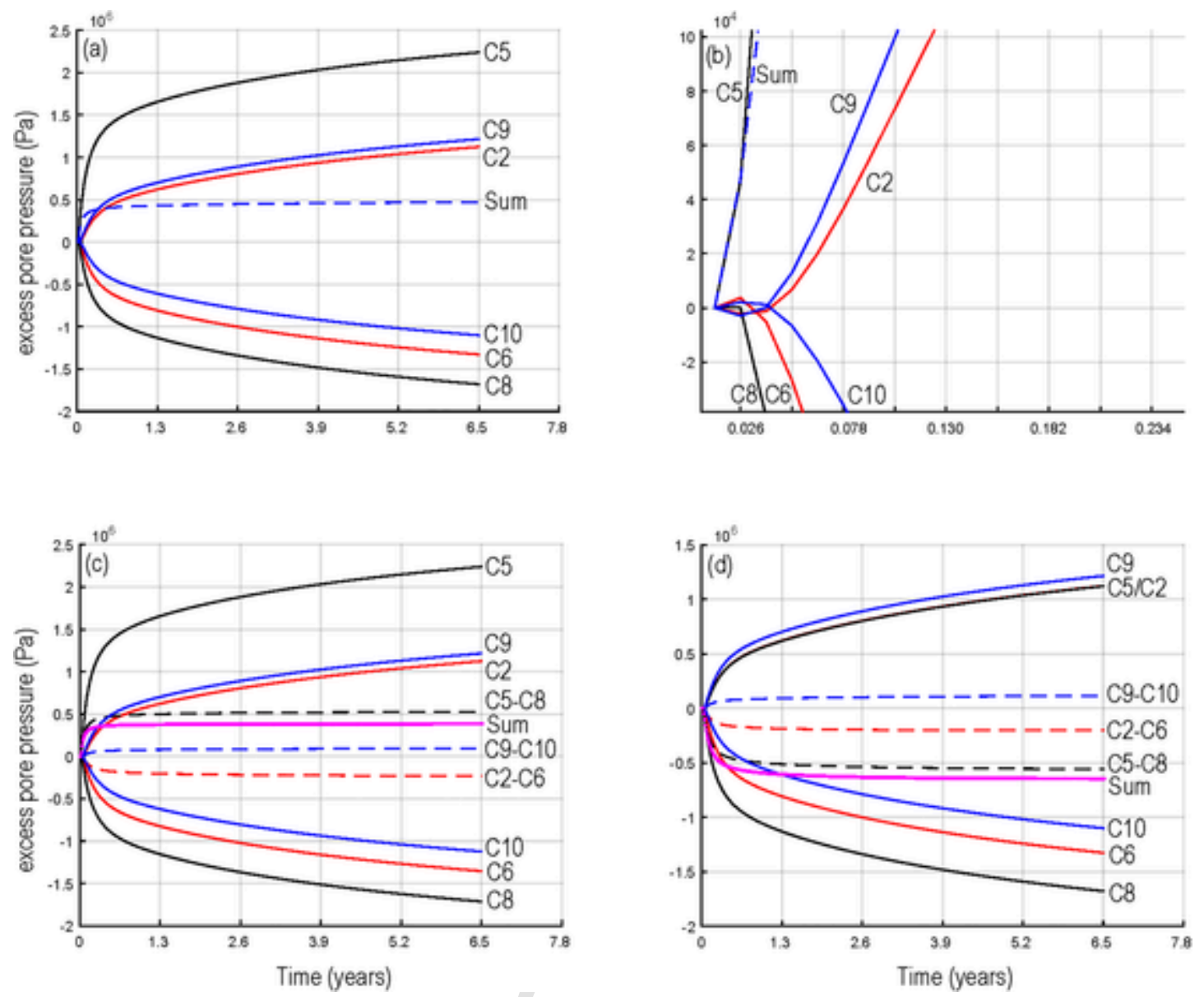

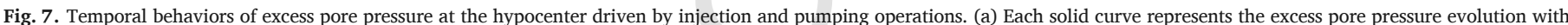

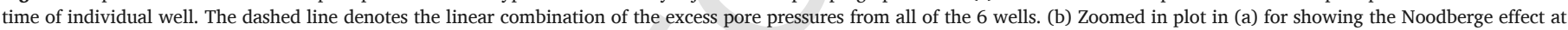

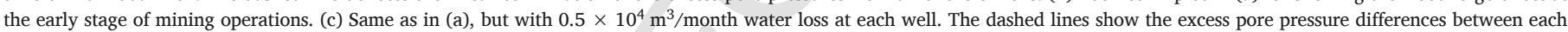

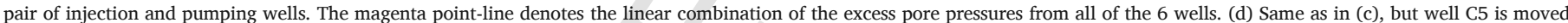

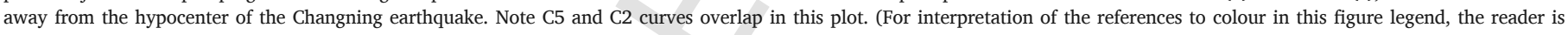
referred to the web version of this article.)

\subsection{Seismogenic Structures of the Changning Event: Fold-Accommodation} Faults

InSAR data reveal that the Changning event is sourced mainly by two fault segments (Figs. 3, 4 and 8): a NW-trending oblique thrust (segment 1) and a WNW-trending sinistral-slip fault (segment 2). These two fault segments are shallow and localized within the NNW-trending portion of the Changning fold, and have slip senses and depths that are significantly different from those of the underlying Changning thrust (Fig. 4b). According to the Coulomb-Mohr law, formation of these two faults requires an ENE-oriented compressional principal stress (Fig. 8b), consistent with the modern stress orientation in the region (Fig. 8a; Jiang et al., 2020; Lei et al., 2019b). It is interesting to note that this orientation is also approximately consistent with the local stress orientation revealed by the fold geometry (Fig. 8a): the fold axis curves from WNW-trending to NNW-trending near these two ruptured faults, indicating an ENE orientation of the maximum principal stress. Combining the shallow and localized development characteristics, we speculate that these two fault segments are fold-accommodation faults (e.g., Cooper, 1992; Tavani et al., 2015): a type of secondary faults formed for accommodating folding deformation. Such faults typically have limited lengths and down-dip extensions, and are consistent with the ruptured fault segments involved in the Changning earthquake. They can be well- and densely-developed within gentle and broad folds and their strike and slip sense can vary at short distances (Fig. 8d; e.g., Cooper, 1992; Tavani et al., 2015; Li et al., 2018), providing prerequisites for cascade rupture of two fault segments with different strike and slip sense. Additionally, such faults are more likely developed and mature in competent carbonate rocks such as dolomite rocks (e.g., Tavani et al., 2015) than in other types of rocks (e.g., metamorphic, igneous, and mudstone). They can facilitate pore pressure increase in dolomite rocks when subject to fluid injection, hence earthquake initiation and large seismic moment release. This may explain why the depth $(2-5 \mathrm{~km}$, Fig. $8 \mathrm{c})$ of the maximum moment release is approximately consistent with the depth (2-3 km, Fig. 8c) of the dolomite rocks.

Overall, we interpret the Changning earthquake as a cascade rupture of fold-accommodation faults in the Changning anticline, shown as segments 1 and 2 in our 

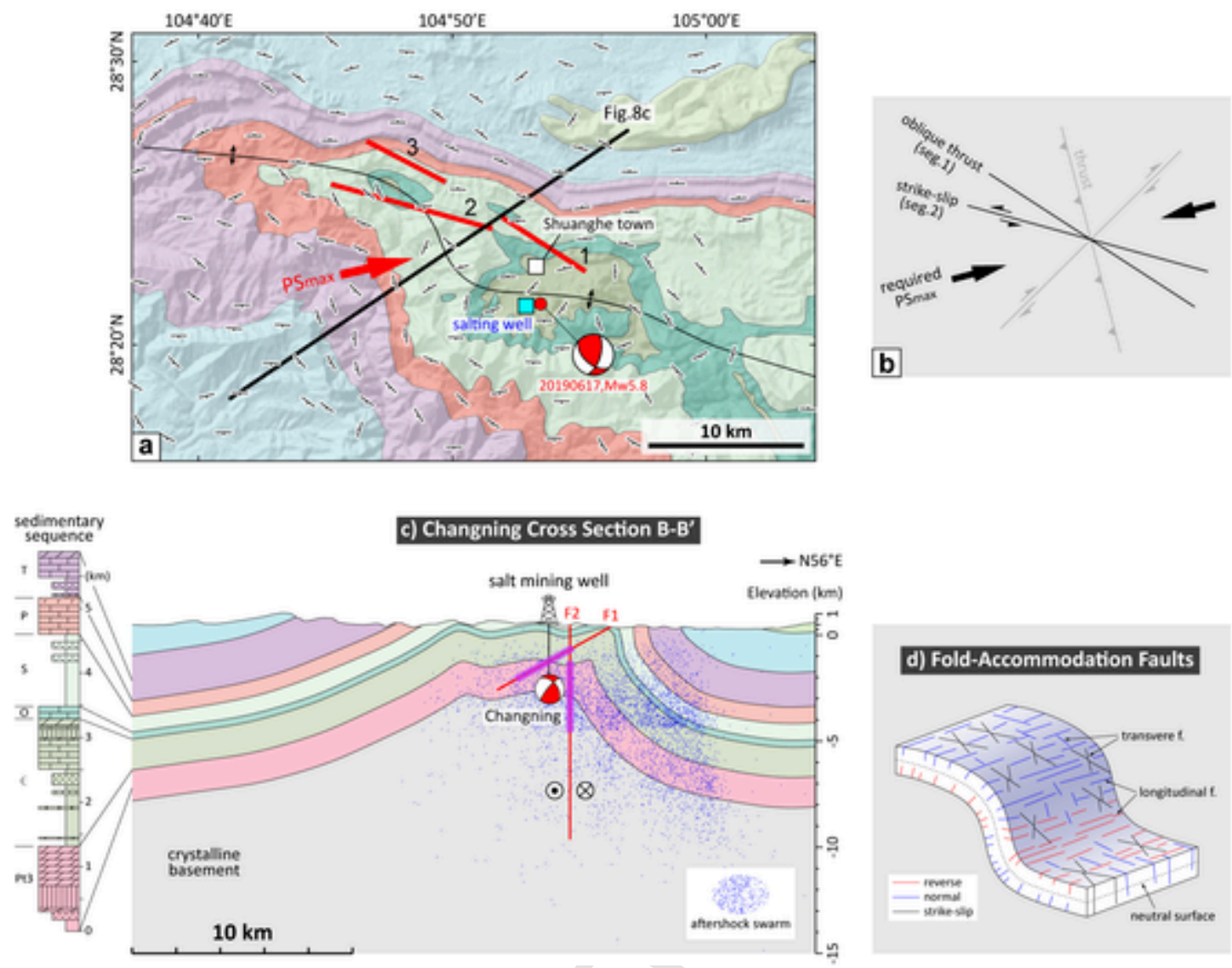

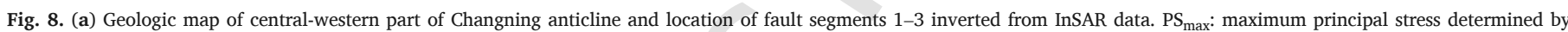

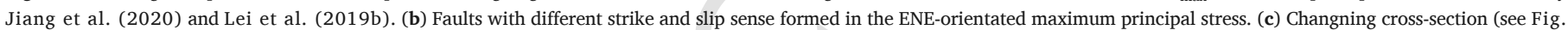

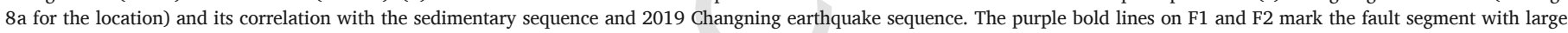

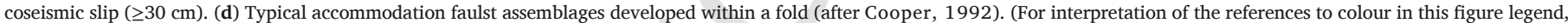
the reader is referred to the web version of this article.)

model. Compared to the $2016 \mathrm{Mw}$ 5.8 Pawnee event in Oklahoma and the $2017 \mathrm{Mw}$ 5.4 Pohang event in South Korea which were not sourced by multiple pre-existing faults (Galloway et al., 2018; Kim et al., 2018; Kolawole et al., 2019), our study shows that the specific nature, location and development characteristics of the fold-accommodation faults increased rupture complexities and cascade-rupture possibilities of injection-induced earthquakes at the Changning region.

\section{Conclusions}

Injection-induced earthquakes have gained widespread concerns because of their possibility of causing damages and economic losses. The existence of deep-rooted faults and their connections with the fluid injection zone are emphasized by recent well-documented studies as the causes of large damaging earthquakes (e.g., Galloway et al., 2018; Grandin et al., 2017; Kim et al., 2018; Kolawole et al., 2019). However, our analysis of the $2019 \mathrm{Mw} 5.8$ Changning event highlights that other scenarios for large rupture are possible, such as cascade rupture of shallower and multiple fold-accommodation faults with different strikes and senses of slip. For the Changning fold, an additional potential for seismic hazard should be considered as well. The shallow injection-induced may also increase static Coulomb stress on the deeper, underlying master thrust (Fig. 2b), or trigger its activity dynamically, and lead to more destructive earthquakes than those sourced by the shallow secondary faults. In contractional tectonic settings dominated by thrust and fold deformation (such as in the Sichuan Basin of China and the sedimentary basin of western Canada), the geometry, kinematics, and stress condition of both fold-accommodation faults and the underlying master thrust are all important factors controlling tectonic deformation, and should be considered for a better assessment of induced-seismicity hazards.

\section{Credit Author Statement}

Jianbao Sun designed the research work and did InSAR data analysis and inversion. Tao Li analyzed geological background and interpreted seismic reflection profiles. Jianbao Sun and Tao Li wrote the paper, with important contributions from Yuxin Bao, Zheng-Kang Shen and Cecile Lasserre. Yuxin Bao plotted supplemental materials in Fig. S1. Yan Zhan and Xiwei $\mathrm{Xu}$ were involved in the discussion of the whole research work.

\section{Uncited reference}

Brodsky and van der Elst, 2014 


\section{Declaration of Competing Interest}

The authors declare that they have no known competing financial interests or personal relationships that could have appeared to influence the work reported in this paper.

\section{Acknowledgments}

This study is funded by the National Natural Science Foundation of China (grant No. 41774043, and No. 41772196), the Institute of Geology, China Earthquake Administration (grant IGCEA1919, IGCEA1920), and the National S\&T Major Project of China (grant 2016ZX05003-001). We thank Lihua Fang, Min Wang, Renqi Lu, Xiangyu Sun, Jing Han, Guixi Yi, Jingfa Zhang, Yongshen Li, Xiaolong Sun, Han Yue, Wanpeng Feng, and Xiaohui He for fruitful discussions. We also appreciate Rongjiang Wang for great help on using his POEL modeling code. We thank Dr. Xinglin Lei, an anonymous reviewer, and Editor Kelin Wang for great help on evaluating this paper and providing wonderful comments, which greatly improve the paper. This work used Copernicus data from the Sentinel-1 satellites provided by the European Space Agency (ESA) through Dragon 4 Programme (No. 32431) and PALSAR-2 data from JAXA through the Sentinel Asia project.

\section{Appendix A. Supplementary data}

Supplementary data to this article can be found online at https://doi. org/10.1016/j.tecto.2021.228721.

\section{References}

Avouac, J.-P., 2012. Human-induced shaking. Nat. Geosci. 5 (11), 763-764.

Bai, M., Chevalier, M.-L., Pan, J., Replumaz, A., Leloup, P.H., Métois, M., Li, H., 2018. Southeastward increase of the late Quaternary slip-rate of the Xianshuihe fault, eastern Tibet. Geodynamic and seismic hazard implications. Earth Planet. Sci. Lett. 485, 19-31.

Biot, M.A., 1941. General theory of three-dimensional consolidation. J. Appl. Phys. 12, 155-164.

Brodsky, E.E., van der Elst, N.J., 2014. The Uses of Dynamic Earthquake triggering. Annu. Rev. Earth Planet. Sci. 42 (1), 317-339.

Burchfiel, B.C., Zhiliang, C., Yupinc, L., Royden, L.H., 1995. Tectonics of the Longmen Shan and Adjacent Regions, Central China. Int. Geol. Rev. 37 (8), 661-735.

Cooper, M., 1992. The analysis of fracture systems in subsurface thrust structures from the Foothills of the Canadian Rockies. In: McClay, K.R. (Ed.), Thrust Tectonics. Springer, Dordrecht, pp. 391-405.

Deng, Q., Zhang, P., Ran, Y., Yang, X., Min, W., and Chu, Q. Z.,2003. Basic characteristics of active tectonics of China. Sci. China Ser. D-Earth Sci., 46(4).

Ellsworth, W.L., 2013. Injection-Induced Earthquakes. Science 341 (6142), 1225942.

Farr, T.G., et al., 2007. The shuttle Radar Topography Mission. Rev. Geophys. 45 (2), 1-33.

Fielding, E.J., Sangha, S.S., Bekaert, D., Samsonov, S., Chang, J.C., 2017. Surface Deformation of North-Central Oklahoma Related to the 2016 Mw 5.8 Pawnee Earthquake from SAR Interferometry Time Series. Seismological Research Letters 88 (4), 971-982

Foulger, G.R., Wilson, M.P., Gluyas, J.G., Julian, B.R., Davies, R.J., 2018. Global review of human-induced earthquakes. Earth Sci. Rev. 178, 438-514.

Galloway, E., Hauck, T., Corlett, H., Pană, D., Schultz, R., 2018. Faults and associated karst collapse suggest conduits for fluid flow that influence hydraulic fracturing-induced seismicity. Proc. Natl. Acad. Sci. 115 (43), E10003.

Grandin, R., Vallée, M., Lacassin, R., 2017. Rupture Process of the Mw 5.8 Pawnee, Oklahoma,
Sentinel-1 InSAR and Seismological Data. Seismol. Res. Lett. 88 (4), 994-1004.

He, D., Lu, R., Huang, H., Wang, X., Jiang, H., Zhang, W., 2019. Tectonic and geological background of the earthquake hazards in Changning shale gas development zone, Sichuan Basin, SW China. Pet. Explor. Dev. 46 (5), 993-1006.

Healy, J.H., Rubey, W.W., Griggs, D.T., Raleigh, C.B., 1968. The Denver earthquakes. Science 161, 1301-1310.

Hincks, T., Aspinall, W., Cooke, R., Gernon, T., 2018. Oklahom's induced seismicity strongly linked to wastewater injection depth. Science 359 (6381), 1251.

Jiang, D., Zhang, S., Ding, R., 2020. Surface deformation and tectonic background of the $2019 \mathrm{M}_{\mathrm{s}}$ 6.0 Changning earthquake, Sichuan Basin, SW China. Journal of Asian Earth Sciences 200104493.

Keranen, K.M., Savage, H.M., Abers, G.A., Cochran, E.S., 2013. Potentially induced earthquakes in Oklahoma, USA: Links between wastewater injection and the $2011 \mathrm{Mw}$ 5.7 earthquake sequence. Geology 41 (6), 699-702.

Kim, K.-H., Ree, J.-H., Kim, Y., Kim, S., Kang, S.Y., Seo, W., 2018. Assessing whether the $2017 \mathrm{Mw}$ 5.4 Pohang earthquake in South Korea was an induced event. Science 360 (6392), 1007.

King, G.C.P., Stein, R.S., Lin, J., 1994. Static stress changes and the triggering of Earthquakes. Bull. Seismol. Soc. Am. 84 (3), 935-953.

Kolawole, F., Johnston, C.S., Morgan, C.B., Chang, J.C., Marfurt, K.J., Lockner, D.A., Reches, Z., Carpenter, B.M., 2019. The susceptibility of Oklahoma's basement to seismic reactivation. Nat. Geosci. 12 (10), 839-844.

Kozłowska, M., Brudzinski, M.R., Friberg, P., Skoumal, R.J., Baxter, N.D., Currie, B.S., 2018. Maturity of nearby faults influences seismic hazard from hydraulic fracturing. Proc. Natl. Acad. Sci. 115 (8), E1720.

Langenbruch, C., Zoback, M.D., 2016. How will induced seismicity in Oklahoma respond to decreased saltwater injection rates? Sci. Adv. 2 (11), e1601542.

Lei, X., Huang, D., Su, J., Jiang, G., Wang, X., Wang, H., Guo, X., Fu, H., 2017. Fault reactivation and earthquakes with magnitudes of up to Mw4.7 induced by shale-gas hydraulic fracturing in Sichuan Basin, China. Scientific Reports 7 (1), 7971.

Lei, X., Wang, Z., Su, J., 2019a. The December 2018 ML 5.7 and January 2019 ML 5.3 Earthquakes in South Sichuan Basin Induced by Shale Gas Hydraulic Fracturing. Seismol. Res. Lett. 90 (3), 1099-1110.

Lei, X., Wang, Z., Su, J., 2019b. Possible link between long-term and short-term water injections and earthquakes in salt mine and shale gas site in Changning, South Sichuan Basin, China. Earth and Planetary Physics 3 (6), 510-525.

Li, Y., Jia, D., Wang, M., Shaw, J.H., He, J., Lin, A., Xiong, L., Rao, G., 2014. Structural geometry of the source region for the $2013 \mathrm{Mw}$ 6.6 Lushan earthquake: Implication for earthquake hazard assessment along the Longmen Shan. Earth Planet. Sci. Lett. 390, 275-286.

Li, T., Chen, J., Thompson Jobe, J.A., Burbank, D.W., Cheng, X., Xu, J., Li, Z., Zheng, W., Zhang, P., 2018. Active Bending-Moment Faulting: Geomorphic Expression, Controlling Conditions, Accommodation of Fold Deformation. Tectonics 37 (8), 2278-2306.

Li, W., Ni, S., Zang, C., Chu, R., 2020. Rupture Directivity of the 2019 Mw 5.8 Changning, Sichuan, China, earthquake and mplication for Induced Seismicity. Bulletin of the Seismological Society of America, XX 1-16. doi:10.1785/0120200013.

Liang, C., Fielding, E.J., 2017. Measuring Azimuth Deformation with L-Band ALOS-2 ScanSAR Interferometry. IEEE Trans. Geosci. Remote Sens. 55 (5), 2725-2738.

Liu, J., Zahradník, J., 2020. The 2019 MW 5.7 Changning Earthquake, Sichuan Basin, China: A Shallow Doublet With Different Faulting Styles. Geophysical Research Letters 47 (4) e2019GL085408.

Manoochehr, S., Ellsworth, W., Tiampo, K.F., González, P.J., Manga, M., 2016. Surface uplift and time-dependent seismic hazard due to fluid injection in eastern Texas. Science 353 (6306), 1416-1419.

Meng, L., McGarr, A., Zhou, L., Zang, Y., 2019. An Investigation of Seismicity Induced by Hydraulic Fracturing in the Sichuan Basin of China based on Data from a Temporary Seismic Network. Bull. Seismol. Soc. Am. 109 (1), 348-357.

Raleigh, C.B., Healy, J.H., Bredehoeft, J.D., 1976. An Experiment in Earthquake Control at Rangely, Colorado. Science 191 (4233), 1230. 
Rosen, P.A., Gurrola, E., Sacco, G.F., Zebker, H., 2012. The InSAR scientific computing environment, paper presented at Synthetic Aperture Radar, 2012. EUSAR. In: 9th European Conference on, 23-26 April 2012.

Schultz, R., Atkinson, G., Eaton, D.W., Gu, Y.J., Kao, H., 2018. Hydraulic fracturing volume is associated with induced earthquake productivity in the Duvernay play. Science 359 (6373), 304.

Segall, P., 1989. Earthquakes triggered by fluid extraction. Geology 17, 942-946.

Strozzi, T., Kouraev, A., Wiesmann, A., Wegmüller, U., Sharov, A., Werner, C., 2008. Estimation of Arctic glacier motion with satellite L-band SAR data. Remote Sens. Environ. 112 (3), 636-645.

Sun, J., Shen, Z.-K., Bürgmann, R., Wang, M., Chen, L., Xu, X., 2013. A three-step Maximum-A-Posteriori probability method for InSAR data inversion of coseismic rupture with application to the April 14, $2010 \mathrm{Mw} 6.9$ Yushu, China earthquake. Journal of Geophysical Research: Solid Earth 118, 4599-4627.

Sun, X., Yang, P., Zhang, Z., 2017. A study of earthquakes induced by water injection in the Changning salt mine area, SW China. J. Asian Earth Sci. 136, 102-109.

Tavani, S., Storti, F., Lacombe, O., Corradetti, A., Muñoz, J.A., Mazzoli, S., 2015. A review of deformation pattern templates in foreland basin systems and fold-and-thrust belts: Implications for the state of stress in the frontal regions of thrust wedges. Earth Sci. Rev. 141, 82-104.

Tian, Y., Kohn, B.P., Qiu, N., Yuan, Y., Hu, S., Gleadow, A.J.W., Zhang, P., 2018. Eocene to Miocene Out-of-Sequence Deformation in the Eastern Tibetan Plateau: Insights from Shortening Structures in the Sichuan Basin. Journal of Geophysical Research: Solid Earth 123 (2), 1840-1855.

Wang, R., Kumpel, H., 2003. Poroelasticity: Efficient modeling of strongly coupled, slow deformation processes in multilayered half-space. GEOPHYSICS 68 (2), 1-13.

Wang M. and Shen Z. K., 2020. Present-Day Crustal Deformation of Continental China Derived from GPS and its Tectonic Implications. Journal of Geophysical Research: Solid Earth, 125, e2019JB018774.
Wang, E., Meng, Q., Burchfiel, B.C., Zhang, G., 2003. Mesozoic large-scale lateral extrusion, rotation, and uplift of the Tongbai-Dabie Shan belt in East China. Geology 31 (4), 307-310.

Wang, E., Meng, K., Su, Z., Meng, Q., Chu, J.J., Chen, Z., Wang, G., Shi, X., Liang, X., 2014. Block rotation: Tectonic response of the Sichuan basin to the southeastward growth of the Tibetan Plateau along the Xianshuihe-Xiaojiang fault. Tectonics 33 (5), 686-718.

Wang, S., Jiang, G., Weingarten, M., Niu, Y., 2020. InSAR evidence indicates a link between fluid injection for salt mining and the 2019 Changning (China) earthquake sequence. Geophysical Res. Letters 47 (16). doi:10.1029/2020GL087603.

Weingarten, M., Ge, S., Godt, J.W., Bekins, B.A., Rubinstein, J.L., 2015. High-rate injection is associated with the increase in U.S. mid-continent seismicity. Science 348 (6241), 1336.

Xu, G., Kamp, P.J.J., 2000. Tectonics and denudation adjacent to the Xianshuihe Fault, eastern Tibetan Plateau: Constraints from ft thermochro. Jour. Geophys. Res. 105, 19231-19251.

Xu, X., Wen, X., Yu, G., Chen, G., Klinger, Y., Hubbard, J., Shaw, J., 2009. Coseismic reverse- and oblique-slip surface faulting generated by the $2008 \mathrm{Mw} 7.9$ Wenchuan earthquake, China. Geology 37 (6), 515-518.

Yang, Z., Shen, C., Ratschbacher, L., Enkelmann, E., Jonckheere, R., Wauschkuhn, B., Dong, Y., 2017. Sichuan Basin and beyond: Eastward foreland growth of the Tibetan Plateau from an integration of late Cretaceous-Cenozoic fission track and (U-Th)/He ages of the eastern Tibetan Plateau, Qinling, and Daba Shan. Journal of Geophysical Research: Solid Earth 122 (6), 4712-4740.

Yi, G., Long, F., Liang, M., Zhao, M., Wang, S., Gong, Y., Qiao, H., Su, J., 2019. Focal mechanism solutions and seismogenic structure of the 17 June 2019 MS6.0 Sichuan Changning earthquake sequence. Chinese Journal of Geophysics (in Chinese) 62 (9), 3432-3447.

Zhu, H., He, C., 2014. Focal Mechanism Changning character of Earthquake Sequence Induced by Water Injection: a Case Study of Changning Sequence, Sichuan Province. Earth Science-Journal of China University of Geosciences 39 (12). 